\section{International Scientific Journal Theoretical \& Applied Science}

p-ISSN: 2308-4944 (print) e-ISSN: 2409-0085 (online)

Year: $2018 \quad$ Issue: $06 \quad$ Volume: 62

Published: $25.06 .2018 \quad$ http://T-Science.org
Aibek Kachkimbaevich Djaparov Adjunct of Academy of Ministry of Interior Affairs of Kyrgyz Republic

Olga Vladimirovna Kovalenko Senior teacher of the department of the criminalistics, special technics and psychology of Academy of Ministry of the Interior Affair of the Kyrgyz Republic lieutenant colonel

SECTION 32. Jurisprudence.

\title{
SPECIFICITY OF PURPOSE AND PRODUCTION SEPARATE KINDS OF FORENSIC EXAMINATIONS (ON THE EXAMPLE OF INVESTIGATION OF CRIMES IN THE SPHERE OF ECOLOGY)
}

Abstract: The specifics of the investigation of the NDVZH, BUT, NPDiK requires extensive use of special knowledge on the study of traces of poaching, without which it is often impossible for the investigator to understand issues from a certain area of knowledge that are known only to specialists of this industry (for example, to what kind of animals belong to the skins ), the solution of which seems to be an important area of the multidisciplinary research, which is especially evident in the aggravation of environmental problems.

Key words: special knowledge; appointment and production of forensic examinations; expertise; expert.

Language: Russian

Citation: Djaparov AK, Kovalenko OV (2018) SPECIFICITY OF PURPOSE AND PRODUCTION SEPARATE KINDS OF FORENSIC EXAMINATIONS (ON THE EXAMPLE OF INVESTIGATION OF CRIMES IN THE SPHERE OF ECOLOGY). ISJ Theoretical \& Applied Science, 06 (62): 61-64.

Soi: http://s-o-i.org/1.1/TAS-06-62-14 Doi: crossef https://dx.doi.org/10.15863/TAS.2018.06.62.14

\section{СПЕЦИФИКА НАЗНАЧЕНИЯ И ПРОИЗВОДСТВА ОТДЕЛЬНЫХ ВИДОВ СУДЕБНЫХ ЭКСПЕРТИЗ (НА ПРИМЕРЕ РАССЛЕДОВАНИЯ ПРЕСТУПЛЕНИЙ В СФЕРЕ ЭКОЛОГИИ)}

Аннотация: Специфика расследования НДВЖ, НО, НПДиК требует широкого использования специильных познаний по исследованию следов браконьерства, без чего следователю, зачастую, невозможно разобраться в вопросах из определенной области знания, которые известны только специиалистам этой отрасли (например, к какому виду животных принадлежат изъятые у подозреваемых шкуры), решение которых представляется важным направлением многоаспектного исследования, что особенно очевидно при обострении экологических проблем.

Ключевые слова: специальные познания; назначение и производство судебных экспертиз; экспертиза; эксперт.

\section{Introduction}

Перед назначением экспертизы следователю необходимо собрать соответствующие материалы и определиться со значением для дела искомой информации, содержащейся в имеющихся вещественных доказательствах, для того чтобы правильно сформулировать вопросы выносимые на разрешение эксперта и получить максимум доказательственной информации.

В этих условиях, Т.Ф. Моисеева справедливо отмечает, что «специфика судебноэкспертных исследований связана не только с их процессуальным характером, но и с важным, порой определяющим значением полученных результатов для расследования и раскрытия преступлений» [1, с.7].

\begin{abstract}
Вопросы, касающиеся процедуры производства судебных экспертиз регламентированы в законе КР «О судебноэкспертной деятельности» [2], УПК КР [3] и других нормативно-правовых актах [4].

Знание задач экспертизы, а также ее объектов и потенциала экспертных исследований имеет важное практическое значение как для подготовки материалов для нее, так и для целенаправленного следственного осмотра различных объектов, что обуславливается результатами экспертизы и расследования НДВЖ, НО, НПДиК в целом. Кроме того, понимание возможностей экспертных исследований назначаемых по данной категории дел, несомненно, способствует объективной
\end{abstract}


оценке и более обширному использованию экспертных заключений при расследовании.

\section{Materials and Methods}

По делам о НДВЖ, НО, НПДиК экспертные исследования могут быть самыми различными, в том числе: трасологические (по исследованию следов человека, транспортных средств и следов животных); оружия и следов выстрела (по исследование огнестрельного оружия и патронов к нему, следов и обстоятельств выстрела а также холодного оружия); маркировочных обозначений; материалов, веществ и изделий (по исследованию волокнистых и лакокрасочных материалов, нефтепродуктов и горюче-смазочных материалов, изделий из металлов и сплавов, стекла и керамики, спиртосодержащих жидкостей, изделий из резины, пластмасс и др.); почвоведческая; биологическая (по исследованию объектов растительного и животного происхождения, биологических следов человека и животных и исследование их видовой принадлежности); судебно-химическая и другие [5].

Вместе с тем, в деятельности ОВД при расследовании преступлений в сфере экологии нередко возникает необходимость в проведении достаточно специфических исследований, которые не получили должного развития в судебно-экспертных органах. Например, в КР существуют большие сложности с проведением следующих видов экспертиз, таких как: ихтиологической, дендрологической, зоотехнической, териологической, орнитологической и др. Проведенное нами исследование показывает, что в практике расследования НДВЖ, НО, НПДиК имеются случаи, когда необходимость производства одной из вышеуказанных экспертиз была весьма очевидной, но она не назначалась, а подменялась актом о самовольной вырубки деревьев, либо актом проверки природоохранной деятельности, либо протоколом о нарушении природоохранного законодательства, либо расчетом стоимости ущерба, на основании Постановления Правительства КР № 403 от 17.08.1992г. «О материальной ответственности за ущерб, причиненный растительному миру КР»,полученными по запросу следователя[6].

По нашему мнению это обусловлено рядом причин, которые заключаются в следующем:

1) бездействие соответствующих органов в обнаружении, пресечении, расследовании и профилактике преступлений связанных с НДВЖ, НО, НПДиК. К примеру, как мы ранее указывали, в г. Бишкек более половины территории парка имени Ататюрка было отдано под частное строительство, где парковые зоны на протяжении
15 лет подвергаются застройке, в котором изначально было 107 гектаров осталось 50 [7];

2) отсутствие в экспертнокриминалистических подразделениях соответствующих специалистов. При интервьюировании практических работников ОВД вышеперечисленные экспертизы не проводятся ни в Государственной судебноэкспертной службе при Правительстве КР, ни в Криминалистическом Управлении МВД КР;

3) слабое материальное обеспечение подразделений органов внутренних дел КР, технико-криминалистическим средствами, позволяющими наиболее полно собирать необходимые доказательства по делу т.д.;

4) коррупцией в государственных структурах [8].

Для наглядности хотелось бы рассмотреть примерный перечень вопросов, которые может задать следователь при назначении отдельных видов экспертиз при расследовании НДВЖ, НО, НПДиК.

К примеру, при назначении ихтиологической экспертизы ставятся такие вопросы, как:

1. к какому семейству относится данная рыба (сиговых, карповых и т.п.);

2. к какому виду относится данная рыба (радужная форель, Иссык-кульский чебак и т.п.);

3. каков пол данной рыбы; половозрелая ли данная рыба;

4. какой рыбе (семейство, вид) принадлежит данное мясо (икра, молока, чешуя, плавник, кости, внутренности и т.п.);

5. из какого количества рыбы могла быть изъята данная икра (молока) [9, с. 26-27].

Вопросы для исследования деревьев, дендрологической и лесотехнической экспертиз следующие:

1. К какому виду деревьев, согласно таксономической классификации, относятся исследуемые деревья?

2. Каков возраст данных деревьев (указать деревья)?

3. Каково состояние данных деревьев?

4. Имеется ли у данных деревьев (указать) лесопатологическое состояние?

5. Каковы причины гибели деревьев (указать деревья)?

6. Какова причина падения деревьев (указать деревья)?

7. Каков возраст поваленных деревьев?

8. В какой промежуток времени произошло падение деревьев?

9. В какой промежуток времени производилась вырубка/валка деревьев?

10. Подлежат ли данные деревья (указать) санитарной вырубке?

11. Определить вид и породу древесины? 
12. Определить качество древесины?

13. Какое количество деревьев было повалено на данном участке местности (указать)?

14. Какие из деревьев были здоровыми, а какие в патологическом состоянии и подлежали санитарной вырубке?

15. Каково количество древесины, фактически выработанное на определенной площади лесоучастка?

16. Правильно ли определено количество древесины на отведенной делянке, лесосеке?

17. Каков объем работ по заготовке древесины и очистке лесосек?

18. Является ли рациональным выбранный способ разделки древесины?

19. Обоснован ли перевод деловой древесины в дровяную?

20. Правильно ли определен фактический выход древесины?

21. Какой объем фактического выхода древесины? [10]

В отношении судебно-биологической экспертизы у ученых имеются различные точки зрения. Так, по мнению Егошина В.В.[11, с. 114115] и Власовой Н.А., [12, с.35] если объектом исследования являются шерсть, куски мяса животного и т.д., то необходимо назначать судебно - биологическую экспертизу, так как все равно придется обращаться к экспертамкриминалистам, биологам, химикам и т.д.

Но мы присоединяемся к позиции И.И. Пиндюры, утверждающего, что «биология - это весьма разветвленная область знаний, имеющая прямое отношение к проблемам среды и реакциям организмов на ее изменение. По своей структуре биология делится на ботанику, гидробиологию, микробиологию, анатомию и зоологию, каждая из которых в свою очередь распадается на многие самостоятельные отрасли знания. В зоологическую науку входят: акарология (наука о клещах), арахнология (наука о паукообразных), гельминтология (наука о паразитических червях), герпетология (наука о земноводных и пресмыкающихся), ихтиология (наука о рыбах), териология (наука о млекопитающих), орнитология (наука о птицах) и др.

Круг вопросов, решаемых в процессе исследования с помощью каждой из перечисленных отраслей знаний, «весьма широк, что обусловлено многообразием и особенностями биологических объектов. Поэтому из названия экспертизы должно ясно вытекать, специалист какой отрасли биологической науки должен быть привлечен к расследованию.

Известно, что животное относится к классу млекопитающих, жизнь и строение которых изучается териологией - наукой о млекопитающих. В этой связи мы полагаем, что с целью исследования животных или зверей следует назначать териологическую экспертизу, а птиц - орнитологическую» [13, с. 72-73].

В зависимости от обстоятельств дела на разрешение териологической или орнитологической экспертиз могут быть поставлены следующие вопросы:

1. Имеются ли на представленных предметах (капканах, ножах, одежде и т.п.) частицы веществ животного происхождения?

2. Если это частицы животного происхождения, то животному или птице и какого вида, они принадлежат?

3. Что собой представляет объект животного происхождения: к какому виду (роду, семейству) животных или птиц он относится?

4. Одному ли виду, группе, семейству животных или птиц принадлежат частицы, обнаруженные на месте происшествия и на орудиях браконьерства, других предметах изъятых у подозреваемого?

5. Составляли ли ранее одно целое части животного или птицы, обнаруженные на месте происшествия, с частью (частями), обнаруженной при обыске подозреваемого (обвиняемого) и другие [13, с. 73-74].

В настоящее время в КР исследования в вышеуказанных областях науки необходимы, прежде всего, в практическом аспекте, ведь сферы применения данных экспертиз не ограничиваются только при рассмотрении административных правонарушений, но и при расследовании преступлений связанных с НДВЖ, НО, НПДиК, контрабандой и т.д. А также по гражданским делам, например, в случаях падения деревьев на транспортные средства где стоит главный вопрос: «Какова причина падения дерева?».

\section{Conclusion}

При анализе судебно-следственной практики нами было выявлено, что ни по одному уголовному делу при расследовании преступлений связанных с рассматриваемыми преступлениями не были назначены и проведены вышеуказанные экспертизы. Практические работники, в случаях необходимости ограничивались только консультативными пояснениями соответствующих специалистов. Однако согласно ст. 81 УПК КР, консультативные мнения специалистов в качестве доказательств по уголовному делу не допустимы.

Все эти недостатки негативно отражаются на результатах исследований, ведут к экспертным и следственным ошибкам, затрудняют процесс оценки результатов следователем и судом. 
Таким образом, в целях максимального использования специальных знаний, с учетом современного состояния судебно-экспертной деятельности в области экологии характеризующейся рядом проблем в кадровом, материально-техническом, научном обеспечении a также исходя из потребностей правоохранительных органов ведущих борьбу с экологическими преступлениями следует:

a) подготовить соответствующих конкурентоспособных специалистов (ихтиологов, дендрологов и др.) на базе отраслевых факультетов соответствующих Вузов (к примеру, Кыргызского национального аграрного университета имени К.И. Скрябина) и научноисследовательских учреждений (Национальной Академии наук КР и т.д.); б) в ближайшее время решить задачу по организации и внедрению в экспертную практику КР таких новых видов исследований как: судебно-дендрологическая, ихтиологическая, териологическая, орнитологическая экспертизы;

в) учитывая несомненную важность экспертных исследований при расследовании преступлений в сфере экологии необходимо регулярно проводить учебно-методические семинары с привлечением сотрудников правоохранительных, природоохранных, экспертных и других учреждений с освещением вопросов проблем возникающих при назначении, производства, оценки заключений экспертов а также порядка оказания помощи соответствующих специалистов.

\section{References:}

1. Moiseeva T.F. (2006) Metodyi i sredstva ekspertnyih issledovaniy: uchebnik. - M.: Moskovskiy psihologo-sotsialnyiy institut, 2006.

2. (2013) Zakon KR ot 24 iyunya 2013 goda \# 100 "O sudebno-ekspertnoy deyatelnosti".

3. (2018) Glava 25 UPK KR.

4. (2013) Polozhenie o Gosudarstvennom tsentre sudebnyih ekspertiz pri Ministerstve yustitsii Kyirgyizskoy Respubliki. Utverzhdeno postanovleniem Pravitelstva Kyirgyizskoy Respubliki ot 22 oktyabrya 2013 goda N 577; Instruktsiya o proizvodstve sudebnyih ekspertiz v Gosudarstvennom tsentre sudebnyih ekspertiz pri Ministerstve yustitsii Kyirgyizskoy Respubliki (Utverzhdena postanovleniem Pravitelstva Kyirgyizskoy Respubliki ot 25 sentyabrya 2012 goda \# 648) i t.d.

5. (2015) Sovmestnyiy prikaz Minyusta KR ot 13 iyulya 2015 goda \# 84, Minzdrava KR ot 1 iyulya 2015 goda \# 376, MVD KR ot 9 iyulya 2015 goda \# 694 i Gossluzhbyi po kontrolyu narkotikov KR ot 8 iyulya 2015 goda \# 100 "Ob utverzhdenii klassifikatora ekspertnyih spetsialnostey, kvalifikatsionnyih trebovaniy, pred'yavlyaemyih $\mathrm{k}$ sudebnyim ekspertam i Polozheniya "Ob organizatsii professionalnoy podgotovki i povyisheniya kvalifikatsii sudebnyih ekspertov".

6. (1980) Ugolovnoe delo \# 103-11-1980; Ugolovnoe delo \# 115-11-24; Ugolovnoe delo \# 114-10-211 i dr.
7. Erik Iriskulbekov (2014) V Bishkeke bolee polovinyi territorii parka imeni Atatyurka otdano pod zastroyku.http://www.24kg.org/community/167 283-yerik-iriskulbekov-v-bishkeke-boleepoloviny.html. Data obrascheniya 16.04.14.

8. (2014) V Bishkekglavarhitekture zaveryayut, chto stroitelstvo razvlekatelnogo tsentra «AlaToo» zalozheno esche v 1979 godu.http://www.24kg.org/bishkek24/166860v-bishkekglavarxitekture-zaveryayut-chto.html Data obrascheniya 16.04.2014.

9. Vlasova N.A. (1995) Metodika rassledovaniya nekotoryih prestupleniy, otnesennyih $\mathrm{k}$ podsledstvennosti organov doznaniya. Uchebnoe posobie. M.: UMTs pri GUK MVD Rossii. 1995.

10. (2015) http://sudmk.ru/dendrologicheskayaekspertiza-voprosy.html. Data obrascheniya 27.05.15.

11. Egoshin V.V. (2002) Metodika rassledovaniya nezakonnoy ohotyi. M.: OOO Izdatelstvo «Yurlitinform», 2002.

12. Vlasova N.A. (1995) Metodika rassledovaniya nekotoryih prestupleniy, otnesennyih $\mathrm{k}$ podsledstvennosti organov doznaniya. Uchebnoe posobie. M.: UMTs pri GUK MVD Rossii. 1995.

13. Pindyur I.I. (1985) Organizatsiya i metodika rassledovaniya nezakonnoy ohotyi: Ucheb.posobie. - Karaganda, 1985. 